\title{
EMERGÊNCIA EM CAMPO DE DICOTILEDÔNEAS INFESTANTES EM SOLO COBERTO COM PALHA DE CANA-DE-AÇÚCAR ${ }^{1}$
}

\author{
DAGOBERTO MARTINS ${ }^{2}$, EDIVALDO D. VELINI ${ }^{2}$, CIBELE C. MARTINS ${ }^{3}$ e LUCIANO S. DE SOUZA ${ }^{4}$
}

\section{RESUMO}

Foram avaliados os efeitos da cobertura do solo com $0,2,4,6,8,10$ e 15 t/ha de palha de cana-de-açúcar da variedade RB 825336 sobre a emergência em campo de plântulas de Sida rhombifolia, Euphorbia heterophylla, Bidens pilosa e Ipomoea grandifolia, introduzidas na área mediante semeadura de 500 sementes viáveis por espécie. Utilizou-se o delineamento em blocos ao acaso com quatro repetições e as unidades experimentais apresentaram dimensões de $2 \times 3 \mathrm{~m}$. Contabilizou-se as plântulas emersas antes e após a remoção da cobertura com palha. A etapa com cobertura de palha do ensaio foi encerrada aos 64 dias após a semeadura, devido à estabilização da emergência em condições, visualmente, inalteradas quanto à quantidade de cobertura de palha e a etapa sem cobertura foi encerrada 119 dias após a remoção da palha. As sementes das espécies de plantas daninhas estudadas apresentam comportamentos germinativos distintos e a cobertura do solo com quantidades crescentes de palha de cana-de-açúcar resultou em padrões de emergência espécie-dependentes. Em condições de cobertura do solo com palha de cana, provável no sistema de colheita da cana crua, as espécies invasoras Bidens pilosa, Euphorbia heterophylla e Ipomoea grandifolia tendem a manter-se como plantas problemas e Sida rhombifolia deverá diminuir sua agressividade, principalmente quando quantidades de palha iguais ou superiores a 6 t/ha foram utilizadas.

Palavras chave: Banco de sementes, dormência, cobertura morta, Saccharum officinalis, planta daninha.

\section{ABSTRACT \\ Broadleaf weed emergence in soil covered with sugar cane straw}

The effect of sugarcane straw over the soil was studied on field conditions on weed seed emergence. The trial witth straw fron RB 825336 sugarcane cultivar was carried out with $0,2,4,6$, 8, 10 and 15 ton/ha amount. The weeds studied were Sida rhombifolia, Euphorbia heterophylla, Bidens pilosa and Ipomoea grandifolia. We used 500 seeds of each weed studied. The research was conducted in randomized completely block design with four replications. The weed emergnece has depended of each weed and amount of sugarcane straw studied. The results showed that increasing in the amount of straw there was decrease on the seed emergence of Sida rhombifolia. To the other weeds, the straw amount that affected the weed emergence was 15 ton/ha only.

Key words: Seed bank, dormancy, mulch, Saccharum officinalis, weed.

\footnotetext{
${ }^{1}$ Recebido para publicação em 11/12/97 e na forma revisada em 18/03/99.

${ }^{2}$ Professor Assistente de Doutor. Depto. Agricultura e Melhoramento Vegetal. FCA/UNESP, C.P..237. CEP 18603-970, Botucatu/SP, Brasil. E-mail: secdamv@fca.unesp.br.

${ }^{3}$ Bolsista Jovem Pesquisador/ FAPESP.

${ }^{4}$ Professor da Faculdade de Agronomia/UNIMAR, Av. Hygino Muzzy Filho, 1001, CEP 17525-000, Marília/SP.
} 


\section{INTRODUÇÃO}

Devido a pressões sociais pela melhoria da qualidade do ar nas cidades circunvizinhas à áreas canavieiras, segundo um esquema de restrições legais progressivas, até o ano de 2012 a queimada da cana-de-açúcar será proibida no Estado de São Paulo (Decreto lei no 41.719 de 16/04/97 e n 45.056 de 17/09/97). Assim, após o corte da cana a palhada permanecerá sobre o solo, realizando-se o manejo cultural sobre uma camada de material orgânico, de modo similar ao sistema de plantio direto do sul do Brasil.

A quantidade, composição, periodicidade da produção, e tempo de permanência da cobertura morta numa área de cana-de-açúcar, que são características que dependem da cultivar, clima e manejo da área, devem determinar a composição da flora infestante e a eficiência do controle das plantas daninhas (Almeida, 1983; Almeida et al., 1983; Almeida \& Rodrigues, 1985). A cobertura morta com palha de cana-de-açúcar variedade SP 71-6163 foi estudada por Lorenzi (1983) e o autor verificou que quantidades superiores a 6 t palha/ha, controlou espécies como Portulaca oleracea, Amaranthus deflexus, Panicum maximum, Eleusine indica e Digitaria horizontalis, emergindo apenas duas plantas por parcela em coberturas com 12 t/ha de palha.

$\mathrm{O}$ efeito da cobertura morta no controle da comunidade infestante vem sendo atribuído a liberação de compostos alelopáticos e a efeitos físicos (Almeida \& Rodrigues, 1985). Características do ambiente podem alterar a produção de compostos alelopáticos, modificando a intensidade dos efeitos encontrados em campo. No sistema de produção de cana crua, caso os compostos alelopáticos estejam presentes na palha, sem a queimada, maiores quantidades dessas substâncias serão liberadas no solo, podendo favorecer o controle de plantas daninhas ou causar reduções de brotações na cultura devido a autointoxicação, de modo similar ao observado, em campo, para Brachiaria brizantha (Rodrigues $\&$ Reis, 1994).
Os efeitos físicos da cobertura morta na comunidade infestante podem ser atribuídos à filtragem da luz, alterando a quantidade e a qualidade do comprimento das ondas luminosas e, à manutenção da temperatura com menores oscilações (Taylorson \& Borthwick, 1969; Fener, 1980 a). As sementes situadas abaixo do perfil de cultivo ou em solo com cobertura morta conseguem manter-se dormentes por maior período de tempo que as situadas na superfície, onde as condições de temperatura, luz e umidade têm maiores oscilações (Martins \& Silva, 1994). Essa característica visa impedir a germinação das sementes em profundidades nas quais as reservas seriam insuficientes para a emergência das plântulas.

As plantas daninhas apresentam sementes dormentes como estratégia de invasão. Fener (1980 a) estudou a germinação de sementes de dezoito espécies infestantes onde detectou que apenas duas eram insensíveis à luz e outras sete espécies, incluindo plantas daninhas importantes para a cultura da cana-de-açúcar, tais como Bidens pilosa e Richardia brasiliensis, apresentaram dormência induzida em sementes expostas a radiação solar filtrada por folhas. Embora os mecanismos gerais de controle da germinação por luz sejam conhecidos, não sabe-se quais são operantes em cada espécie vegetal.

Esse trabalho teve por objetivo avaliar os efeitos da cobertura do solo com a palha de canade-açúcar sobre a emergência de Sida rhombifolia, Euphorbia heterophylla, Bidens pilosa e Ipomoea grandifolia que são espécies dicotiledôneas infestantes dessa cultura.

\section{MATERIAL E MÉTODOS}

O experimento foi conduzido na Fazenda experimental São Manoel, pertencente à UNESP e localizada no município de São Manoel, no Estado de São Paulo, em solo do tipo Latossolo Vermelho Amarelo álico A moderado, textura média, fase cerrado tropical. Não foram utilizados 
fertilizantes ou corretivos. As características químicas da terra utilizada no experimento foram: $\mathrm{pH}\left(\mathrm{CaCl}_{2}\right)=4,7 ;$ M.O. $(\mathrm{g} / \mathrm{kg})=17,0 ; \mathrm{P}=4,0$ $\mathrm{mg} / \mathrm{dm}^{3} ; \mathrm{H}+\mathrm{Al}, \mathrm{K}, \mathrm{Ca}, \mathrm{Mg}, \mathrm{SB}$ e $\mathrm{CTC}=3,2,1,6$, $8,0,5,0,14,6$ e $17,8 \mathrm{meq} / 100 \mathrm{~cm}^{3}$, respectivamente $\mathrm{e}, \mathrm{V} \%=82$.

A área experimental foi preparada através de uma aração e três gradagens, destorroando-se completamente o solo. Após essas operações, foram demarcadas as unidades experimentais, em número de 32 , com dimensões de $2 \times 3 \mathrm{~m}$. Utilizou-se o delineamento em blocos ao acaso com quatro repetições, avaliando-se os efeitos da cobertura do solo com $0,2,4,6,8,10$ e 15 t/ha de palha de cana da variedade RB 825336 , sobre a emergência de quatro espécies dicotiledôneas daninhas de importância para a cultura da cana-deaçúcar: Sida rhombifolia L. (guanxuma), Euphorbia heterophylla L. (leiteiro), Bidens pilosa L. (picão-preto) e Ipomoea grandifolia (Dammer) O'Don. (corda-de-viola). A área experimental apresentava infestação próxima de zero ou nula das espécies em estudo. As sementes utilizadas no ensaio apresentavam taxas de germinação, avaliadas em laboratório, de 40\%, 90\%, $80 \%$ e $45 \%$, respectivamente.
As sementes das plantas daninhas foram semeadas nas parcelas, na primeira quinzena de maio, utilizando-se molduras metálicas de $0,5 \mathrm{~m} \mathrm{x}$ $0,5 \mathrm{~m}$, cravadas no solo até $10 \mathrm{~cm}$ de profundidade na região central das parcelas. Em cada um desses quadros, em número de quatro por parcela, foi semeada uma das espécies de dicotiledôneas em estudo, determinando-se por sorteio a posição de cada uma das espécies. A taxa de semeadura foi determinada para que houvessem 500 sementes viáveis por quadro $\mathrm{e}$ as sementes foram incorporadas manualmente aos $3 \mathrm{~cm}$ superficiais do solo. Após a semeadura cada parcela recebeu a palha de cana, distribuída em camada uniforme e em quantidade referente a cada tratamento. Nesse processo, para facilitar a visualização da área a ser coberta, foi utilizada uma moldura de madeira com $15 \mathrm{~cm}$ de altura sobre a parcela.

Foi realizada a irrigação da área no dia da semeadura e quando não ocorreram chuvas, a cada três dias até o final do experimento com $5 \mathrm{~mm} /$ dia de água, para que as sementes das plantas daninhas tivessem disponibilidade de água para germinar. Na Tabela 1 são apresentados os dados de temperatura e precipitação do local vigentes durante a condução do experimento.

Tabela 1. Precipitações acumuladas e médias das temperaturas mínimas, médias e máximas diárias, para cada mês, durante o período de condução do experimento na fazenda São Manuel/ SP, 1997.

\begin{tabular}{lcccc}
\hline \multicolumn{1}{c}{ Mês } & $\begin{array}{c}\text { Precipitação } \\
(\mathrm{mm})\end{array}$ & \multicolumn{3}{c}{ Médias das temperaturas $\left({ }^{\circ} \mathrm{C}\right)$} \\
\cline { 3 - 5 } & 136 & 13,16 & Máximas & Médias \\
\hline Maio & 194 & 10,97 & 23,71 & 18,44 \\
Junho & 32 & 12,94 & 20,07 & 15,52 \\
Julho & 19 & 13,52 & 24,29 & 18,61 \\
Agosto & 159 & 15,33 & 25,65 & 19,58 \\
Setembro & 215 & 15,81 & 28,10 & 21,72 \\
Outubro & 235 & 18,07 & 27,35 & 21,58 \\
Novembro & & & 28,67 & 23,37 \\
\hline
\end{tabular}

O ensaio compreendeu duas fases distintas. Na primeira fase foram avaliadas as plântulas emersas em solo com cobertura de palha de cana e, na segunda, a emergência após a remoção da palha.

O número de plântulas emersas em solo com palha de cana foi avaliada aos 13,29, 43 e 64 (d.a.s.), realizando-se a identificação das espécies, a contabilização e o arranquio de cada uma das plântulas. Foram consideradas emersas, as plântulas visíveis em cada avaliação e com mais de $1 \mathrm{~cm}$ de parte aérea, ainda que dentro da camada de palha. 
As avaliações foram encerradas aos 64 d.a.s., duas ou três avaliações após a estabilização do número de plântulas emersas, dependendo da espécie. Na última avaliação a camada de palha de cana foi removida, secada e pesada. Com os valores do peso final (f) e inicial da palha (i), foram calculadas a quantidade de palha decomposta (d), pela fórmula $\mathrm{d}=\mathrm{i}-\mathrm{f}$; e a taxa de decomposição $(\mathrm{Td})$, pela fórmula: $\mathrm{Td}(\%)=$ $100 \mathrm{~d} / \mathrm{i}$.

Aos 38, 65, 91 e 119 dias após a remoção da cobertura com palha de cana (d.r.p.), avaliou-se o número de plântulas emersas, realizando-se a identificação das espécies semeadas, a contabilização e o arranquio de cada uma das plântulas. Nesse caso, também, foram consideradas emersas as plântulas com mais de 1 $\mathrm{cm}$ de parte aérea. As avaliações foram encerradas aos 119 d.r.p., devido à estabilização do número de plântulas e à dificuldade no controle de plantas daninhas, principalmente Raphanus sativus L., que infestaram a área experimental.

Os números totais de plântulas emersas antes e após a remoção da cobertura com palha, e a soma dos totais das duas fases do ensaio, foram submetidos a análise de variância, utilizando-se níveis de probabilidade de $10 \%, 5 \%$ e $1 \%$ e comparando-se as médias com o auxílio do teste $\mathbf{t}$, ao nível de $10 \%$ de probabilidade.

\section{RESULTADOS E DISCUSSÃO}

A quantidade da palha da cana-de-açúcar decomposta foi diretamente proporcional à quantidade aplicada, inicialmente, em cobertura (Tabela 2). Assim, quanto maior a quantidade de palha utilizada na cobertura da parcela, maior a quantidade do material que foi decomposto e viceversa.

Tabela 2. Quantidade de palha de cana-de-açúcar inicial, final e decomposta sobre a superfície do solo e taxa de decomposição. Médias dos tratamentos utilizados. São Manuel/ SP, 1997.

\begin{tabular}{cccc}
\hline & Quantidade de palha (t/ha) & Taxa de decomposição \\
\cline { 1 - 3 } Inicial & Final & Decomposta & 7,50 \\
\hline 2 & 1,85 & 0,15 & 32,50 \\
4 & 2,70 & 1,30 & 27,83 \\
6 & 4,33 & 1,67 & 26,38 \\
8 & 5,89 & 2,11 & 24,09 \\
10 & 7,59 & 2,41 & 23,13 \\
15 & 11,53 & 3,47 & \\
\hline
\end{tabular}

No entanto, quando considerou-se a taxa de decomposição, os resultados mostraram que, a partir de $4 \mathrm{t} / \mathrm{ha}$, quanto maior a quantidade de palha aplicada em cobertura mais difícil tornou-se a decomposição do material. Tratando-se de área anteriormente utilizada no sistema de plantio convencional espera-se que a população microbiana da área do experimento tivesse atingido um patamar adequado à disponibilidade de material orgânico do período anterior ao ensaio e que não foi suficiente para decompor, com a mesma rapidez, quantidades maiores de material orgânico. No entanto, em condições de solo quase descoberto, com 2 t/ha de palha, a pior taxa de decomposição $(7,50 \%)$, muito inferior à observada nas condições de cobertura máxima, com 15 t/ha de palha $(23,13 \%)$, deve ser atribuída a oscilações térmicas e de umidade prejudiciais à população de microorganismos do solo (Almeida \& Rodrigues, 1985).

Para minimizar os efeitos das alterações das quantidades de palha dos tratamentos, ensaios similares a esse devem ter a menor duração possível, embora a taxa de decomposição dependa das condições edafoclimáticas da área. A primeira fase do presente ensaio, com cobertura de palha, foi encerrada aos 64 d.a.s., devido à estabilização da emergência em condições, visualmente, inalterados quanto à quantidade de cobertura de palha. 
Quanto à emergência de plântulas, a cobertura do solo, com quantidades crescentes de palha de cana-de-açúcar, resultou em padrões de emergência espécie-dependentes.

Para S. rhombifolia, a presença da cobertura do solo com palha reduziu significativamente a emergência das plântulas e esse efeito foi mais intenso quanto maior a quantidade de palha utilizada (Figura 1 e Tabela 3). No entanto, a remoção da cobertura promoveu a emergência das plântulas dessa espécie, principalmente nos tratamentos de 4 a $10 \mathrm{t}$ de palha/ha, devido a superação da dormência causada ou mantida pela cobertura morta. O número de plântulas emersas demonstrou que a manutenção de quantidades iguais ou superiores a 2 t/ha de palha de cana como cobertura do solo, por pelo menos 64 dias, favoreceu significativamente o controle das plântulas de $S$. rhombifolia. Em condição de área plantada com cana, esse período de tempo seria suficiente para o fechamento da área e controle das plantas infestantes por sombreamento.

Os tratamentos com 2 e 15 t/ha, apresentaram respostas diferenciadas do conjunto, influenciadas pela aparente morte das sementes. A cobertura com $2 \mathrm{t} / \mathrm{ha}$ de palha, por ser muito rala, não deve ter alterado as condições de luz e de temperatura o suficiente para impedir a superação da dormência das sementes, pois isso resultaria no implemento da emergência após a remoção da palha. Assim, antes da remoção da cobertura, o número significativamente menor de plântulas emersas desse tratamento, em comparação à testemunha deve ter sido causado pela morte das sementes, devido, talvez, à predação. Em estudos que envolvem bancos de sementes deve-se ter em vista os animais, que interagindo com o banco através do enterrio e predação podem interferir nos resultados (Martins \& Silva, 1994).

A cobertura com 15 t/ha de palha proporcionou a maior inibição à emergência de plântulas de S. rhombifolia antes e após a remoção da palha, o que resultou no menor número total de plântulas emersas, devido à morte das sementes, causada, provavelmente, por compostos alelopáticos liberados pela palha da cana-de açúcar.

Para E. heterophylla, a presença da cobertura em qualquer das quantidades de palha testadas, não afetou a emergência das plântulas. Entretanto, a retirada da cobertura morta dos tratamentos de 10 e $15 \mathrm{t} /$ ha de palha estimulou a emergência (Figura 2 e Tabela 4). Esse efeito, provavelmente, foi causado pelo contraste térmico ou de luz que levam à superação da dormência das sementes e contribuem para o aumento da emergência total de plântulas do período de avaliação (Carvalho \& Nakagawa, 1988; Martins \& Silva, 1994). Portanto, no sistema de corte da cana crua, E. heterophylla deverá continuar a representar um problema, como planta infestante.

$\mathrm{O}$ efeito dos tratamentos sobre o número total de plântulas emersas não foi significativo aos níveis de probabilidade testados, mas sim a $12,56 \%$ (d.m.s. $=28,65 \%$ ). Nessas condições, as médias dos tratamentos de 10 e 15 t/ha de palha ratificaram os dados de plântulas emersas após a remoção da cobertura.

Para B. pilosa, em comparação à testemunha (0 t/ha), a presença da cobertura morta com palha de cana nas quantidades de 2 a 6 t/ha implementou a emergência das plântulas; nas quantidades de 8 a 10 t/ha não afetou a emergência, e na quantidade de 15 t/ha, inibiu a emergência (Figura 3 e Tabela 5). Com a retirada da cobertura de palha, a emergência das plântulas ocorreu em todos os tratamentos de modo similar, demonstrando que as sementes de B. pilosa não apresentaram dormência causada ou mantida pela cobertura morta. Fener (1980b) relatou que $B$. pilosa não apresenta dormência dependente da luz.

Os resultados indicam que, no sistema de produção da cana crua, $B$. pilosa continuará a representar um problema, como planta infestante.

Para I. grandifolia, em comparação à testemunha $(0 \mathrm{t} / \mathrm{ha})$, a presença da cobertura implementou a emergência das plântulas apenas nas quantidades de 2 a 8 t/ha de palha de cana (Figura 4 e Tabela 6). A retirada da cobertura não 
promoveu, em comparação à testemunha, a emergência das plântulas dos tratamentos, nivelando os resultados do total de plântulas emersas. Esse comportamento assemelhou-se ao observado para $B$. pilosa e demonstrou que as sementes não apresentaram dormência causada ou mantida pela cobertura morta.
Após a remoção da palha de cana o aumento da emergência de plântulas, proporcional a quantidade de cobertura inicialmente aplicada, deve-se a um efeito, provavelmente, químico residual e, para E. heterophylla e I. grandifolia esse comportamento é observado em canaviais.
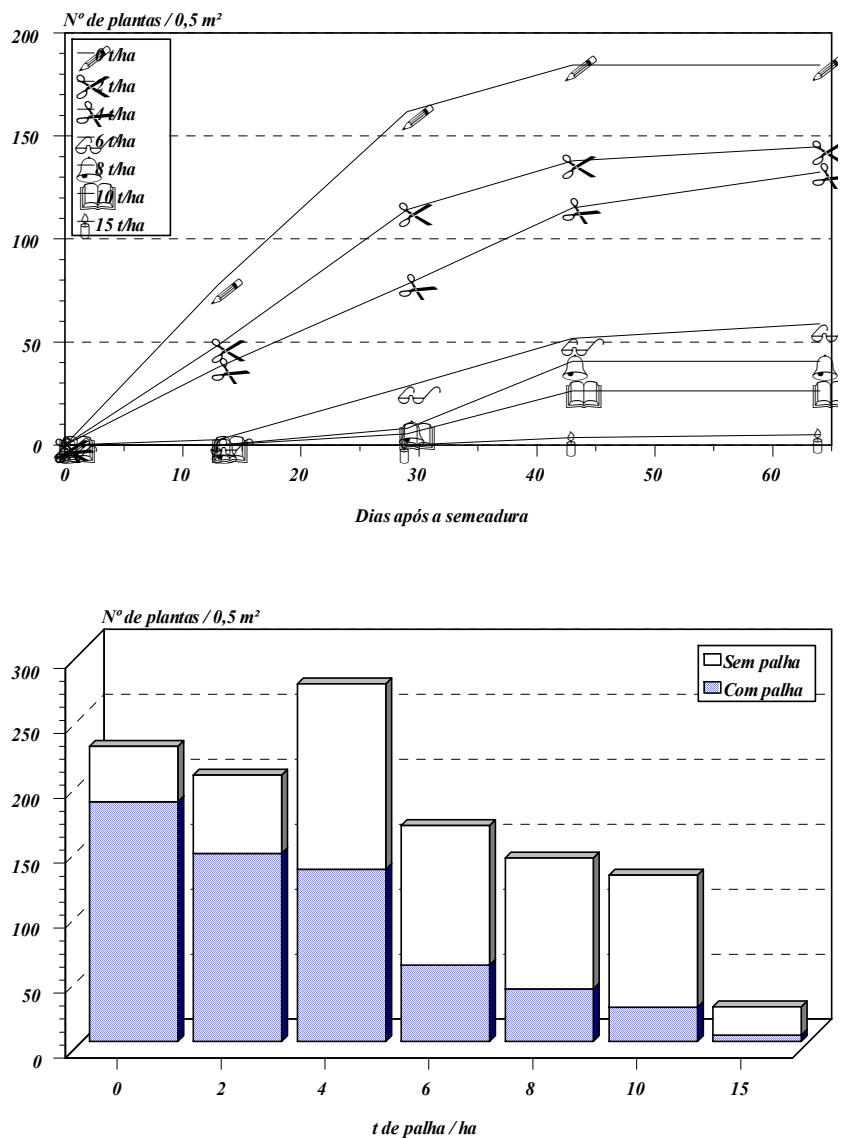

FIGURA 1. Resultados referentes à germinação de Sida rhombifolia. Representação da germinação ao longo do tempo, durante o período inicial com cobertura com palha de cana-de-açúcar (Gráfico superior). No gráfico inferior são apresentados os números totais de plantas germinadas no período com cobertura, após a eliminação da mesma e o total destas duas etapas (somas das duas seções das barras). UNESP / Botucatu - 1997. 
Tabela 3. Número de plântulas de Sida rhombifolia emersas antes e após a remoção da cobertura com palha de cana, no total das duas fases. São Manuel/ SP, 1997. São Manuel/ SP, 1997.

\begin{tabular}{|c|c|c|c|}
\hline \multirow{2}{*}{$\begin{array}{l}\text { Quantidade de palha } \\
\qquad(\mathrm{t} / \mathrm{ha})\end{array}$} & \multicolumn{3}{|c|}{ Plântulas Emersas $\left(\mathrm{n}^{\circ} / 0,5 \mathrm{~m}^{2}\right)$} \\
\hline & Antes da remoção & Após a remoção & Total \\
\hline 0 & 184,50 a & $42,75 \mathrm{~d}$ & $227,25 \mathrm{ab}$ \\
\hline 2 & $144,75 \mathrm{~b}$ & $60,25 \mathrm{~cd}$ & $205,00 \mathrm{bc}$ \\
\hline 4 & $132,50 \mathrm{~b}$ & 143,00 a & 275,50 a \\
\hline 6 & $58,75 \mathrm{c}$ & $107,50 \mathrm{ab}$ & $166,25 \mathrm{~cd}$ \\
\hline 8 & $40,50 \mathrm{~cd}$ & 100,75 bc & $141,25 \mathrm{~d}$ \\
\hline 10 & $26,25 \mathrm{~cd}$ & $102,00 \quad b$ & $128,25 \mathrm{~d}$ \\
\hline 15 & $5,00 \mathrm{~d}$ & $21,75 \mathrm{~d}$ & $26,75 \mathrm{e}$ \\
\hline F blocos & $1,64^{\mathrm{ns}}$ & $3,66^{* *}$ & 2,04 \\
\hline $\mathrm{F}$ tratamentos & $17,94^{* * *}$ & $6,51^{* * *}$ & $12,91^{* * * *}$ \\
\hline C.V. $(\%)$ & 38,30 & 40,22 & 26,74 \\
\hline d.m.s. (t a $10 \%)$ & 39,72 & 40,72 & 54,81 \\
\hline
\end{tabular}

Médias seguidas pela mesma letra na coluna não diferem entre si pelo teste $\mathrm{t}$.

ns: não significativo;* significativo ao nível de 10\%; ** significativo ao nível de 5\%;*** significativo ao nível de $10 \%$.
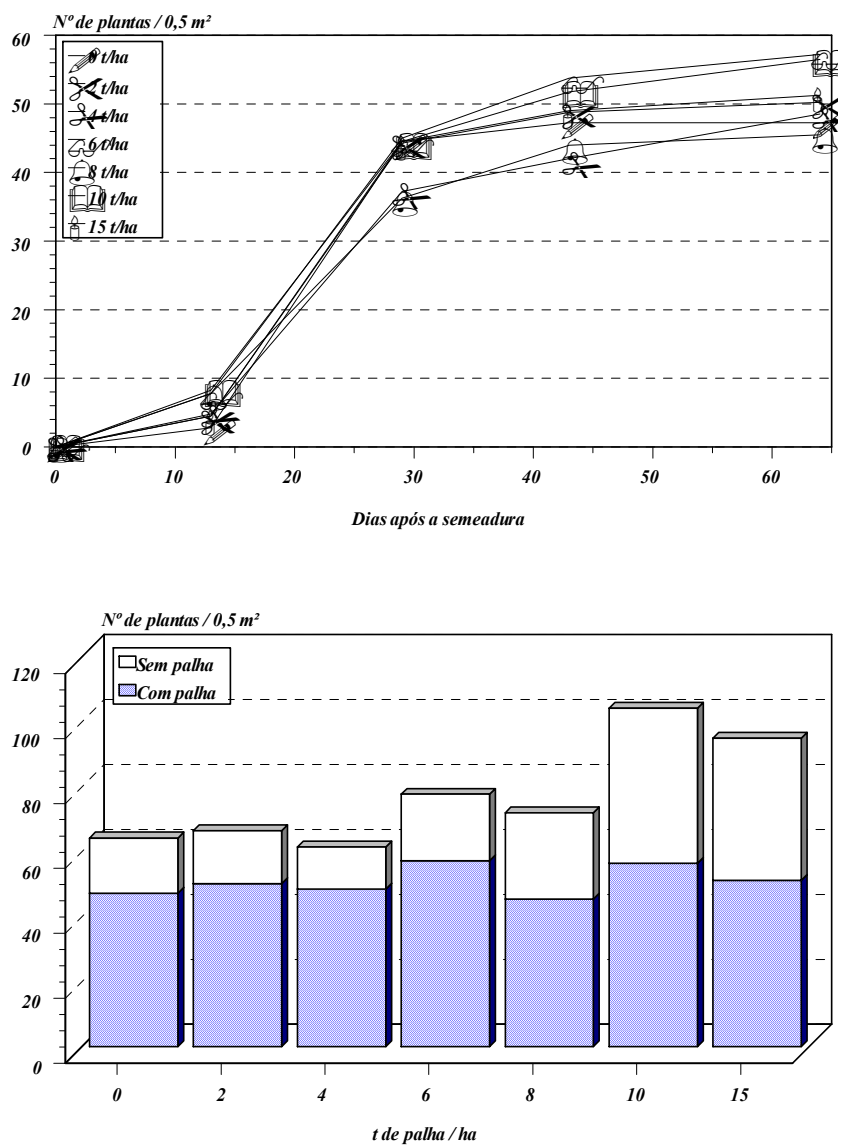

FIGURA 2. Resultados referentes à germinação de Euphorbia heterophylla. Representação da germinação ao longo do tempo, durante o período inicial com cobertura com palha de cana-de-açúcar (Gráfico superior). No gráfico inferior são apresentados os números totais de plantas germinadas no período com cobertura, após a eliminação da mesma e o total destas duas etapas (somas das duas seções das barras). UNESP / Botucatu - 1997. 
Tabela 4. Número de plântulas de Euphorbia heterophylla emersas antes e após a remoção da cobertura com palha de cana e no total das duas fases. São Manuel/ SP, 1997.

\begin{tabular}{cccc}
\hline \multirow{2}{*}{$\begin{array}{c}\text { Quantidade de } \\
\text { palha (t/ha) }\end{array}$} & \multicolumn{3}{c}{ Plântulas Emersas $\left(\mathrm{n}^{\circ} / 0,5 \mathrm{~m}^{2}\right)$} \\
\cline { 2 - 4 } & Antes da remoção & Após a remoção & Total \\
\hline 0 & 47,25 & $17,00 \mathrm{~b}$ & 64,25 \\
2 & 50,25 & $16,25 \mathrm{~b}$ & 66,50 \\
4 & 48,50 & $13,00 \mathrm{~b}$ & 61,50 \\
6 & 57,25 & $20,50 \mathrm{~b}$ & 77,75 \\
8 & 45,50 & $26,50 \mathrm{~b}$ & 72,00 \\
10 & 56,50 & $47,75 \mathrm{a}$ & 104,25 \\
15 & 51,25 & $43,75 \mathrm{a}$ & 95,00 \\
\hline F blocos & 4,57 ** & 0,70 ns & $2,68 *$ \\
F tratamentos & 0,25 ns & 4,26 *** & $1,966^{\text {ns }}$ \\
C.V. (\%) & 35,45 & 51,09 & 30,22 \\
\hline d.m.s. (t a 10\%) & - & 16,53 & - \\
\hline
\end{tabular}

Médias seguidas pela mesma letra na coluna não diferem entre si pelo teste $t$.

ns: não significativo;* significativo ao nível de 10\%; ** significativo ao nível de 5\%;*** significativo ao nível de $10 \%$.
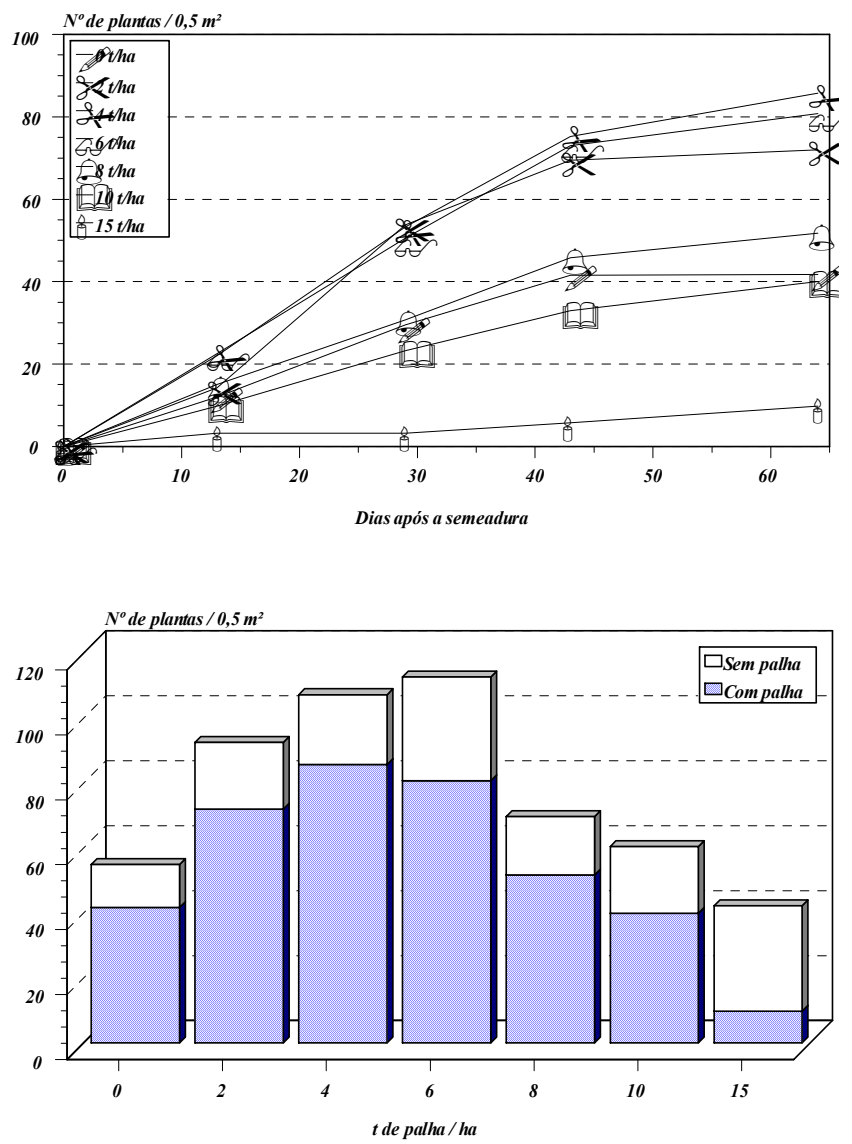

FIGURA 3. Resultados referentes à germinação de Bidens pilosa. Representação da germinação ao longo do tempo, durante o período inicial com cobertura com palha de cana-de-açúcar (Gráfico superior). No gráfico inferior são apresentados os números totais de plantas germinadas no período com cobertura, após a eliminação da mesma e o total destas duas etapas (somas das duas seções das barras). UNESP / Botucatu - 1997. 
Tabela 5. Número de plântulas de Bidens pilosa emersas antes e após a remoção da cobertura com palhade cana e no total das duas fases. São Manuel/ SP, 1997.

\begin{tabular}{|c|c|c|c|}
\hline \multirow{2}{*}{$\begin{array}{l}\text { Quantidade de } \\
\text { palha (t/ha) }\end{array}$} & \multicolumn{3}{|c|}{ Plântulas Emersas $(\mathrm{n}$ / 0,5 m²) } \\
\hline & Antes da remoção & Após a remoção & Total \\
\hline 0 & $41,75 \mathrm{c}$ & 13,25 & $55,00 \mathrm{Cd}$ \\
\hline 2 & $72,00 \mathrm{ab}$ & 20,50 & $92,50 \mathrm{Ab}$ \\
\hline 4 & 85,75 a & 21,50 & $107,25 \mathrm{~A}$ \\
\hline 6 & 80,75 a & 32,00 & $112,75 \mathrm{~A}$ \\
\hline 8 & 51,75 bc & 18,00 & $69,75 \mathrm{Bc}$ \\
\hline 10 & $40,00 \mathrm{c}$ & 20,50 & $60,50 \mathrm{Cd}$ \\
\hline 15 & $9,75 \mathrm{~d}$ & 32,50 & $42,25 \mathrm{D}$ \\
\hline F blocos & $3,11 *$ & $0,95^{\mathrm{ns}}$ & $2,46^{*}$ \\
\hline F tratamentos & $7,86 * * *$ & $1,78 \mathrm{~ns}$ & $7,39^{* * *}$ \\
\hline C.V. $(\%)$ & 35,24 & 47,32 & 25,97 \\
\hline d.m.s. (t a $10 \%$ ) & 23,56 & - & 24,57 \\
\hline
\end{tabular}

Médias seguidas pela mesma letra na coluna não diferem entre si pelo teste t.

ns: não significativo; * significativo ao nível de 10\%; ** significativo ao nível de 5\%;*** significativo ao nível de $10 \%$.
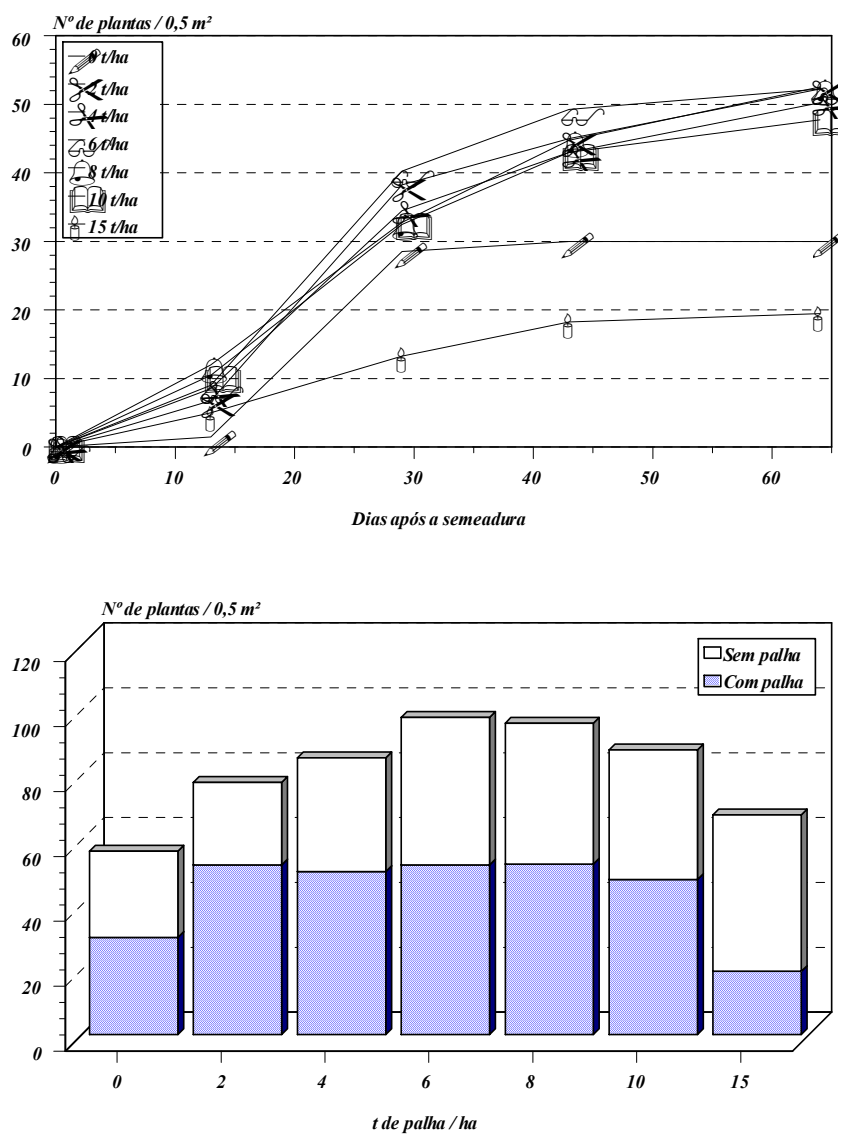

FIGURA 4. Resultados referentes à germinação de Ipomoea grandifolia. Representação da germinação ao longo do tempo, durante o período inicial com cobertura com palha de cana-de-açúcar (Gráfico superior). No gráfico inferior são apresentados os números totais de plantas germinadas no período com cobertura, após a eliminação da mesma e o total destas duas etapas (somas das duas seções das barras). UNESP / Botucatu - 1997. 
Tabela 6. Número de plântulas de Ipomoea grandifolia emersas antes e após a remoção da cobertura com palha de cana e no total das duas fases. São Manuel/ SP, 1997.

\begin{tabular}{|c|c|c|c|}
\hline \multirow{2}{*}{$\begin{array}{l}\text { Quantidade de } \\
\text { palha (t/ha) }\end{array}$} & \multicolumn{3}{|c|}{ Plântulas Emersas $\left(\mathrm{n}^{\circ} / 0,5 \mathrm{~m}^{2}\right)$} \\
\hline & Antes da remoção & Após a remoção & Tota \\
\hline 0 & $30,00 \mathrm{bc}$ & 26,50 & 56,50 \\
\hline 2 & 52,25 a & 25,50 & 77,75 \\
\hline 4 & 50,25 a & 35,00 & 85,25 \\
\hline 6 & 52,25 a & 45,50 & 97,75 \\
\hline 8 & 52,50 a & 43,50 & 96,00 \\
\hline 10 & $47,75 \mathrm{ab}$ & 40,00 & 87,75 \\
\hline 15 & $19,50 \mathrm{c}$ & 48,25 & 67,75 \\
\hline F blocos & $1,45^{\mathrm{ns}}$ & $0,48^{\mathrm{ns}}$ & $0,83^{\mathrm{ns}}$ \\
\hline F tratamentos & $3,16^{* *}$ & 0,61 ns & $1,15^{\mathrm{ns}}$ \\
\hline C.V. $(\%)$ & 34,29 & 61,32 & 34,53 \\
\hline d.m.s. (t a 10\%) & 18,29 & - & - \\
\hline
\end{tabular}

Médias seguidas pela mesma letra na coluna não diferem entre si pelo teste $\mathrm{t}$.

ns: não significativo;* significativo ao nível de 10\%; ** significativo ao nível de 5\%;*** significativo ao nível de $10 \%$.

É necessário determinar a natureza dos efeitos da palha da cana sobre as sementes e o processo de germinação. Efeitos similares, mas com diferentes causas, podem levar à adoção de diferentes condutas técnicas para o controle das plantas invasoras. É importante avaliar-se a presença de depósitos de palha, pontualmente, nas áreas com colheita de cana crua, quanto à uniformidade na quantidade e distribuição, para que possa-se estimar adequadamente o potencial de invasão de cada uma das espécies de planta daninha.

As sementes das espécies de plantas daninhas estudadas apresentam comportamentos germinativos distintos e a cobertura do solo com quantidades crescentes de palha de cana-de-açúcar resultou em padrões de emergência espéciedependentes.

Em condições de cobertura do solo com palha de cana, provável no sistema de colheita da cana crua, as espécies invasoras B. pilosa, E. heterophylla e I. grandifolia tendem a manter-se como plantas problemas e $S$. rhombifolia deverá diminuir sua agressividade, principalmente quando quantidades de palha iguais ou superiores a $6 \mathrm{t} / \mathrm{ha}$ foram utilizadas.

\section{LITERATURA CITADA}

ALMEIDA, F.S. Levantamento da evolução e incidência de plantas daninhas. In: VIEIRA, M. Avaliação de sistemas de cultivo em rotações de culturas. Londrina, IAPAR, 1983. p.9-11. (Relatório)

ALMEIDA, F.S.; RODRIGUES, B.N. Guia de herbicidas. Londrina: IAPAR, 1. Ed. Livroceres.1985.

ALMEIDA, F.S.; RODRIGUES, B.N.; OLIVEIRA, V.F. Resultados de pesquisa da área de herbologia do IAPAR, da safra de 1982/83. Londrina, IAPAR, 1983, 167p. (Relatório)

CARVALHO, N.M.; NAKAGAWA, J. Sementes: ciência, tecnologia e produção. 3.ed. Campinas: Fundação Cargill, 1988. 424p. 
FENER, M. Germination tests of thirthy-two East African weed species. Weed Res., v.20, p. 135-8, 1980 a.

FENER, M. The induction of a light requirement in Bidens pilosa seeds by leaf canopy shade. New Phytology, v.84, p. 103, 1980 b.

LORENZI, H. Efeito da palha da cana no controle das plantas daninhas. IN: CONGRESSO BRASILEIRO DE HERBICIDAS E PLANTAS DANINHAS, 19, 1993. Resumos... Londrina, 1993. p. 28-29.

MARTINS, C.C.; SILVA, W.R. Estudos de bancos de sementes do solo. Info. Abrates, Londrina, v.4, n.1, p.49-56, 1994

RODRIGUES, L.R.A.; REIS, R.A.. Estabelecimento de outras forrageiras em áreas de Brachiaria spp. IN: SIMPÓSIO SOBRE MANEJO DA PASTAGEM, 11, 1994. Anais... Piracicaba: FEALQ, 1994. p. 299-325.

TAYLORSON, R.B.; BORTHWICK, H.A.A. Light filtration by foliar canopies: significance for light-controlled weeseed germination. Weed Sci., v.17, n.1, p.48-51, 1969. 